\title{
BMJ Open Utilisation willingness for institutional care by the elderly: a comparative study of empty nesters and non-empty nesters in Shandong, China
}

Yangyang Qian, ${ }^{1}$ Wen Qin, ${ }^{2}$ Chengchao Zhou, ${ }^{1,3}$ Dandan Ge, ${ }^{1}$ Li Zhang, ${ }^{1}$ Long Sun ${ }^{1}$

To cite: Qian Y, Qin W, Zhou C, et al. Utilisation willingness for institutional care by the elderly: a comparative study of empty nesters and non-empty nesters in Shandong, China. BMJ Open 2018:8:e022324. doi:10.1136/ bmjopen-2018-022324

- Prepublication history and additional material for this paper are available online. To view these files, please visit the journal online (http://dx.doi. org/10.1136/bmjopen-2018022324).

$Y Q$ and $W Q$ contributed equally.

$Y Q$ and $W Q$ are co-first authors.

Received 24 February 2018

Revised 26 June 2018

Accepted 13 July 2018

Check for updates

(c) Author(s) (or their employer(s)) 2018. Re-use permitted under CC BY-NC. No commercial re-use. See rights and permissions. Published by BMJ.

${ }^{1}$ School of Public Health, Shandong University, Jinan, China

${ }^{2}$ Shandong University Hospital, Shandong University, Jinan, Shandong, China

${ }^{3}$ Key Lab of Health Economics and Policy Research, Shandong University, Jinan, China

Correspondence to

Professor Chengchao Zhou;

zhouchengchao@sdu.edu.cn

\section{ABSTRACT}

Introduction Institutional care has been strongly promoted in China to meet seniors' long-term care needs. Empty-nest elderly, in comparison with their counterparts, have less social support and fewer caring networks. This study aimed to compare the utilisation willingness for institutional care and its predictors between empty-nest and non-empty-nest seniors.

Methods A total of 3923 seniors were included in the analysis. Binary logistic regression models were used to understand the association between the living arrangements of the elderly households and willingness for institutional care and to identify the predictors of the utilisation willingness for institutional care among empty nesters and non-empty nesters.

Results Our study found that approximately $8.5 \%$ of the seniors had a willingness for institutional care in Shandong, China. Empty-nest singles (OR 5.301; 95\% Cl 2.838 to 9.904 ) and empty-nest couples (OR 1.547; $95 \% \mathrm{Cl} 1.135$ to 2.107 ) were found to be more willing to receive institutional care. Our results also showed that residence was a key determinant for institutionalisation willingness in empty-nest and non-empty-nest elderly. Among empty-nest singles, psychological stress was a positive determinant for institutional care. Factors, including education attainment, relationship with adult children, household income and per capita living space, were determinants for empty-nest couple willingness for institutionalisation. Age, number of children and selfreported health status were found to be associated factors for willingness among non-empty nesters.

Conclusions The government should pay more attention to institutional care in rural areas where there is still a gap in elder care compared with that in urban areas. Targeted policies should be made for different types of seniors to offer appropriate institutional care.

\section{INTRODUCTION}

Since 1999, the proportion of seniors aged 60 and above among the general population in China has reached more than $10 \%$, and the number of people in the ageing population in China has ranked the first in the world. ${ }^{1}$ The number of Chinese people aged 60 years and above reached 212.4 million by 2014 ,

\section{Strengths and limitations of this study}

- A large sample of 3923 participants based on a community survey provided a real profile of willingness for institutional care in Chinese seniors.

- There might be a possible recall bias for most questionnaire data, which is a limitation of this study.

- The cross-sectional study design precludes any causal interpretation.

which accounted for $15.5 \%$ of the total population. ${ }^{2}$ It has been estimated that China, with 98.3 million old people aged 80 or over in 2050 , will still be one of the countries that has the greatest numbers of oldest-to-old people. ${ }^{3}$ With the rapid ageing of the Chinese population, the number of empty nesters is on the rise as well. ${ }^{4}$ Empty-nest seniors are those seniors who are childless or whose children have already left home. ${ }^{5}$ With the increasing number of elderly empty nesters, long-term care for the elderly has been emerging as a social problem.

Traditionally, taking care of the elderly by adult children in the family was a basic norm within Confucian doctrine. ${ }^{6}$ In recent years, increased geographical mobility and reduced family size due to the one-child policy have made more adult children unavailable for elder care. ${ }^{7}$ Intergenerational relations are also changing; thus, elderly support is no longer considered an absolute obligation by adult children. ${ }^{8}$ More women in urban China are obtaining a higher education and becoming more work oriented, which indicates that gender roles in elder care are changing, and the availability of elder care by adult children has become questionable. ${ }^{10}$ On the other hand, with Chinese 'baby boomers' approaching retirement age, informal care, such as familial care, is unlikely to meet the needs of all seniors. ${ }^{11}$ One study indicated that nearly half of the seniors who 
needed some level of assistance in their activities of daily living (ADL) or instrumental ADL actually lived alone instead of living with their adult children. ${ }^{10}$ Another study found that many seniors expressed preference to live alone or with their spouse, if housing and health status permitted. ${ }^{12}$ Consequently, institutional care has been strongly promoted to meet older adults' long-term care needs. $^{13}$

After the welfare reform in 1990s, former government-sponsored nursing homes have become decentralised, and the amount of private nursing homes is on the rise, mostly emerging in large cities. ${ }^{7}$ Previous studies have identified the attitudes of empty-nest elderly towards institutional care and its predictors. Some studies found that the rate of institutional care of the Chinese elderly was rapidly on the rise, which might be due to the elderly increasing need. ${ }^{14}{ }^{15}$ A study found that seniors' living arrangements prior to elder home placement and their assessment of the cost involved for such care were related to seniors' willingness to stay in elder homes. ${ }^{16}$ Some other studies found that factors, including gender, educational attainment, occupation, health insurance and number of children, were associated with willingness for institutional care among the empty-nest seniors. ${ }^{17-19}$ However, only a few of these studies were published in international journals. Moreover, the studies described earlier had some systematic weaknesses. First, almost all of the empirical studies were based on small sample sizes (eg, $\mathrm{n}=523$ in the case of Xie $e t a l ; n=570$ in the case of Chen; $\mathrm{n}=1000$ in the case of Zhu et al) ${ }^{17-19}$ Second, in many studies, it was not clear who served as the reference group. In other words, the associated factors were only explored in empty-nest seniors. ${ }^{17-19}$

To remedy this situation, the present study aimed to compare the willingness to use institutional care between empty-nest and non-empty-nest seniors in China. To do so, we had the following specific objectives. First, we compared the willingness for institutional care between empty-nest and non-empty-nest elderly. Second, we identified the associated factors for institutional care among the empty-nest and non-empty-nest elderly. Our study was an empirical study and was not guided by theory.

\section{METHODS}

\section{Data}

This study was conducted in Shandong, a province where the elderly aged 65 or over accounted for $11.6 \%$ of the total population. ${ }^{20}$ In this study, a three-stage cluster sampling was used to select participants, as described in detail previously. ${ }^{21}$ A total of 3923 older people were included in the analysis. We used a face-to-face interview to collect data from November 2011 to January 2012. The interviews were conducted by trained master students from Shandong University School of Public Health. To ensure quality, completed questionnaires were carefully checked by quality supervisors at the end of each day. The questionnaire included demographic characteristics, living arrangements of the households, relationship with children, marital status, economic status, mental health condition and willingness for institutional care.

\section{Variables and measures}

The dependent variable was seniors' willingness for institutional care, which was evaluated on the grounds of participant answers to "which endowment way are you willing for?' If the response was 'institutional care', the willingness for institutional care was coded as 'yes'. In contrast, if the answer was 'home-based care', 'community endowment' or 'others', willingness for institutional care was coded as 'no'.

Sociodemographic and psychological characteristics such as gender, age, education, past occupation (preretirement occupation), marital status, number of children, relationship with children, residence, self-reported health status, psychological stress, ADL, non-communicable diseases (NCDs) and household income were included in this study.

The age of the participants was categorised as follows: 60-, 70- and 80+ years. Other demographic characteristics were classified as follows: gender (male vs female), education (illiteracy or semiliterate, primary school and junior school or above), past occupation (farmer vs others), marital status (single vs couple), number of children (0-3 vs $>3)$, relationship with children (good vs bad), residence (urban vs rural), self-reported health status (good vs normal or poor), ADL ( $\square-\mathrm{III})$, NCDs in the past 6 months (yes vs no) and household income (Q1-Q4). Quartile 1 (Q1) is the poorest and Quartile 4 (Q4) is the richest.

The living arrangements of elderly households were classified into non-empty nester, empty-nest single and empty-nest couple. Non-empty nester refers to those seniors who live with their children, while empty-nest single and empty-nest couple refer to those seniors who live alone without a spouse and with a spouse, respectively, for more than 6 months. ${ }^{22}$ Per capita living space is a measure that takes total living space (square metre) and divides it by the number of permanent people (who live in the house more than half a year) in a house.

Psychological stress was evaluated on the grounds of the 10-item Kessler Scale (K10). K10 is an effective tool to assess people's psychological status and was designed by scholars such as Kessler and Mroczek..$^{23}$ The Chinese-language version of the K10 has been verified to have good reliability and validity. ${ }^{24}$

The ADL instrument consisted of the Physical Self-maintenance Scale and Instrumental ADL Scale designed by Lawton and Brody. ${ }^{25}$ The ADL Scale was used to evaluate people's simple and basic ability to practise one's normal life independently. The reliability and validity of the ADL instrument in the Chinese-language version were demonstrated to be good. ${ }^{26}$ Scores for ADL can be divided into three levels, with the higher level representing more severe dysfunction. Levels 1, 2 and 3 
Table 1 Sociodemographic characteristics of the elderly in Shandong, China $(n=3923)$

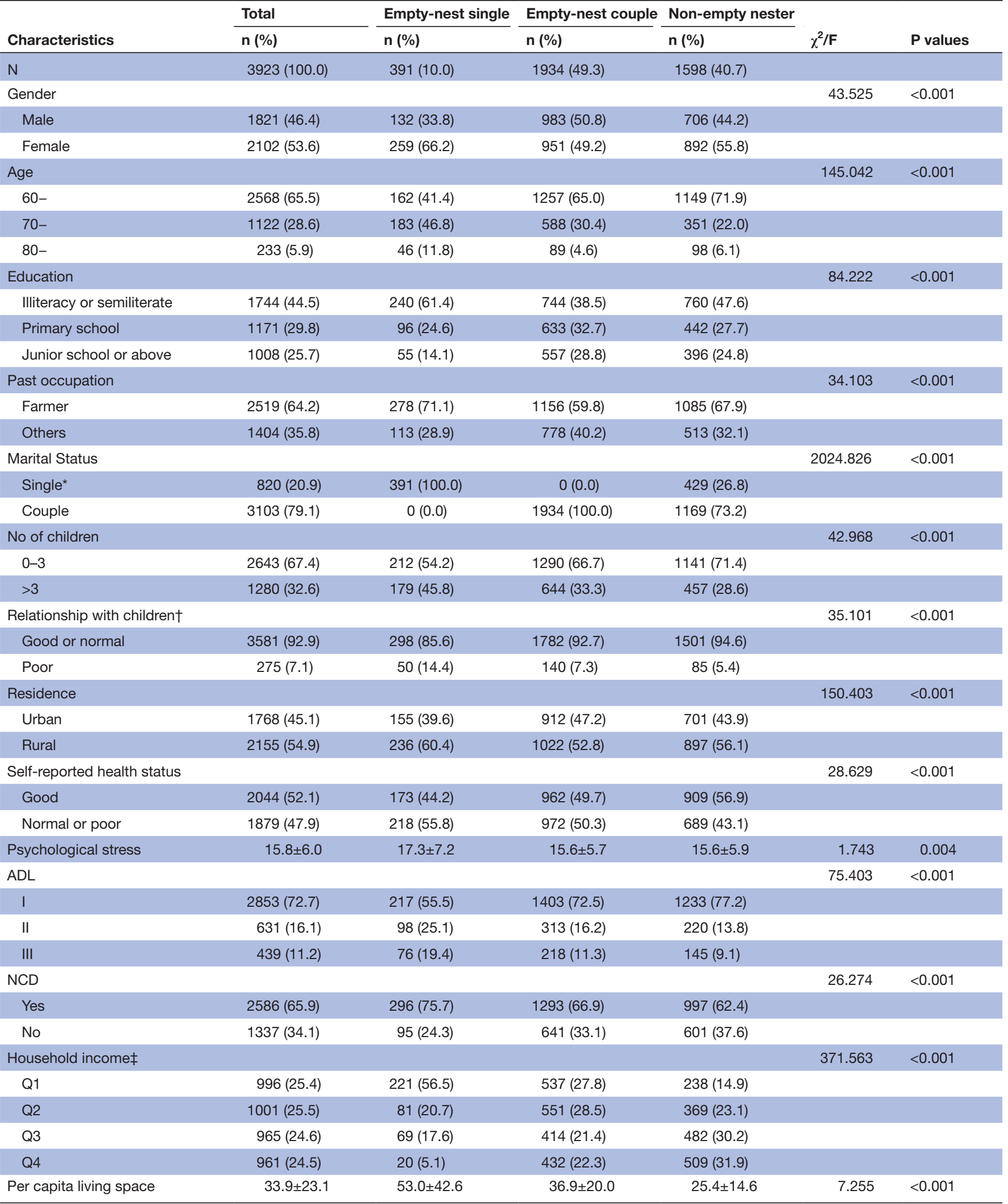

*Single includes those who were unmarried $(1.7 \%)$, divorced $(0.3 \%)$, widowed $(18.6 \%)$ or separated $(0.3 \%)$.

$\dagger$ Sixty-seven of the participants were childless elders and were regarded as missing data here.

‡Quartile 1 (Q1) is the poorest and Quartile 4 (Q4) is the richest.

$A D L$, activities of daily living; NCD, non-communicable disease. 
mean mild dysfunction, moderate dysfunction and severe dysfunction, respectively. ${ }^{27}$

We also present the variables and assignments in online supplementary appendix table 1.

\section{Statistical analysis}

The data were double entered and checked using EpiData V.6.04. Statistical analyses were performed using SPSS V.21.0. For continuous variables, $p$ values were calculated using a Student's t-test or F-test; for categorical variables, $p$ values were calculated using a $\chi^{2}$ test. Two binary logistic regression models were employed to assess the association between living arrangements of elderly households and willingness for institutional care. We used a univariate logistic regression model and multivariate logistic regression model to explore the factors associated with willingness for institutional care. All reported CIs were calculated at the $95 \%$ level. Statistical significance was set at the $5 \%$ level.

\section{Patient and public involvement statement}

Neither patients nor the public were involved in the development of the research question, in the analysis and in drawing conclusions from the results. The results in this study will provide evidence for policy-makers and will not be disseminated to the study participants.

\section{RESULTS}

Table 1 shows basic information on the 3923 seniors. Approximately $8.5 \%$ seniors indicated willingness for institutional care. Non-empty nesters accounted for $40.7 \%$ of the participants, empty-nest singles accounted for $10.0 \%$ and empty-nest couples accounted for $49.3 \%$. Generally, the majority of the elderly were female $(53.6 \%)$, between the ages of 60 and $69(65.5 \%)$, illiterate or semiliterate $(44.5 \%)$, farmers $(64.2 \%)$, couples $(79.1 \%)$, having $0-3$ children $(67.4 \%)$, having a good or normal relationship with their children $(91.3 \%)$, rural $(54.9 \%)$, having good self-reported health status $(52.1 \%)$, having mild dysfunction $(72.7 \%)$ and having NCDs $(65.9 \%)$. The elderly's K10 score was $15.8 \pm 6.0(\mathrm{M} \pm \mathrm{SD})$, and their per capita living space was $33.9 \pm 23.1(\mathrm{M} \pm \mathrm{SD})$ square metres.

We presented our results in two models to understand the association between living arrangements of elderly households and willingness for institutional care. Model 1 showed that willingness for institutional care was higher in empty-nest singles (OR 2.759; 95\% CI 1.974 to 3.857) and empty-nest couples (OR 1.340; 95\% CI 1.038 to 1.729 ) than that in non-empty nesters. When other variables were controlled, willingness for institutional care was still higher among empty-nest singles (OR 5.301; 95\% CI 2.838 to 9.904 ) and empty-nest couples (OR 1.547 ; $95 \%$ CI 1.135 to 2.107 ) than that in non-empty nesters (table 2). Figure 1 shows that in each of the three subgroups with different household living arrangements, urban seniors' willingness to use institutional care was statistically higher than that of rural seniors.
Table 3 shows the factors associated with willingness for institutional care among empty-nest singles. Univariate analysis indicated that empty-nest singles who were from rural areas $(p<0.001)$ had lower willingness for institutional care. Empty-nest singles who had greater psychological stress $(p=0.050)$ had higher willingness for institutional care. Multivariate logistic analysis also showed that the two factors were associated with willingness for institutional care.

As shown in table 4, univariate analysis showed that those empty-nest couples who had a higher education level, who were non-farmers $(\mathrm{p}<0.001)$, who had a poor relationship with their children $(\mathrm{p}=0.014)$ and who had higher household incomes were more willing for institutional care. Those empty-nest couples who had more than three children $(\mathrm{p}=0.040)$, who lived in rural areas $(\mathrm{p}<0.001)$, who had severe dysfunction $(\mathrm{p}=0.003)$ and who had more per capita living space $(\mathrm{p}=0.019)$ were less willing for institutional care. Multilogistic regression indicated that factors including education level, relationship with children, household income and residence were associated with willingness for institutional care.

Likewise, for those non-empty-nest seniors, the multilogistic regression model found that those with younger age, those who had fewer children, those who were from urban areas and those who had a normal or poor selfrated health status preferred to use institutional care (see table 5).

\section{DISCUSSION}

Our study found that $8.5 \%$ of the seniors had willingness for institutional care. This rate was lower than the that found among Korean American elders (45\%) with a similar age. ${ }^{28}$ This rate was lower than the reported rates of $20 \%$ in an urban area and $17 \%$ in a rural area in the elderly in China and $16.7 \%$ in a study of the seniors aged 65 or above in Taiwan, China. This rate was also lower than the $9.69 \%$ found in an older population in Zhejiang, China, and $44.8 \%$ found in a study in the elderly with a similar age in Chengdu, China. ${ }^{13}{ }^{29-31}$ Compared with the above-mentioned sites, Shandong is a rather conservative province that is deeply affected by Confucianism. The culture of filial piety is profoundly rooted in Shandong residents' minds. This might be a primary cause of the variation between our study and the previous studies mentioned above.

Our results showed that living arrangements of the households were associated with the elderly willingness for institutional care. The analysis made it clear that emptynest singles and empty-nest couples were more willing for institutional care than non-empty nesters. This finding was consistent with another study that found that older adults who had no spouse or children were more likely to move into nursing homes than their counterparts. ${ }^{732}$ Due to lack of care from adult children, empty-nest seniors are facing more endowment risks. Empty-nest elderly had poorer self-rated health, higher prevalence of 2-week 
Table 2 Association of willingness for institutional care and household composition in Shandong, China

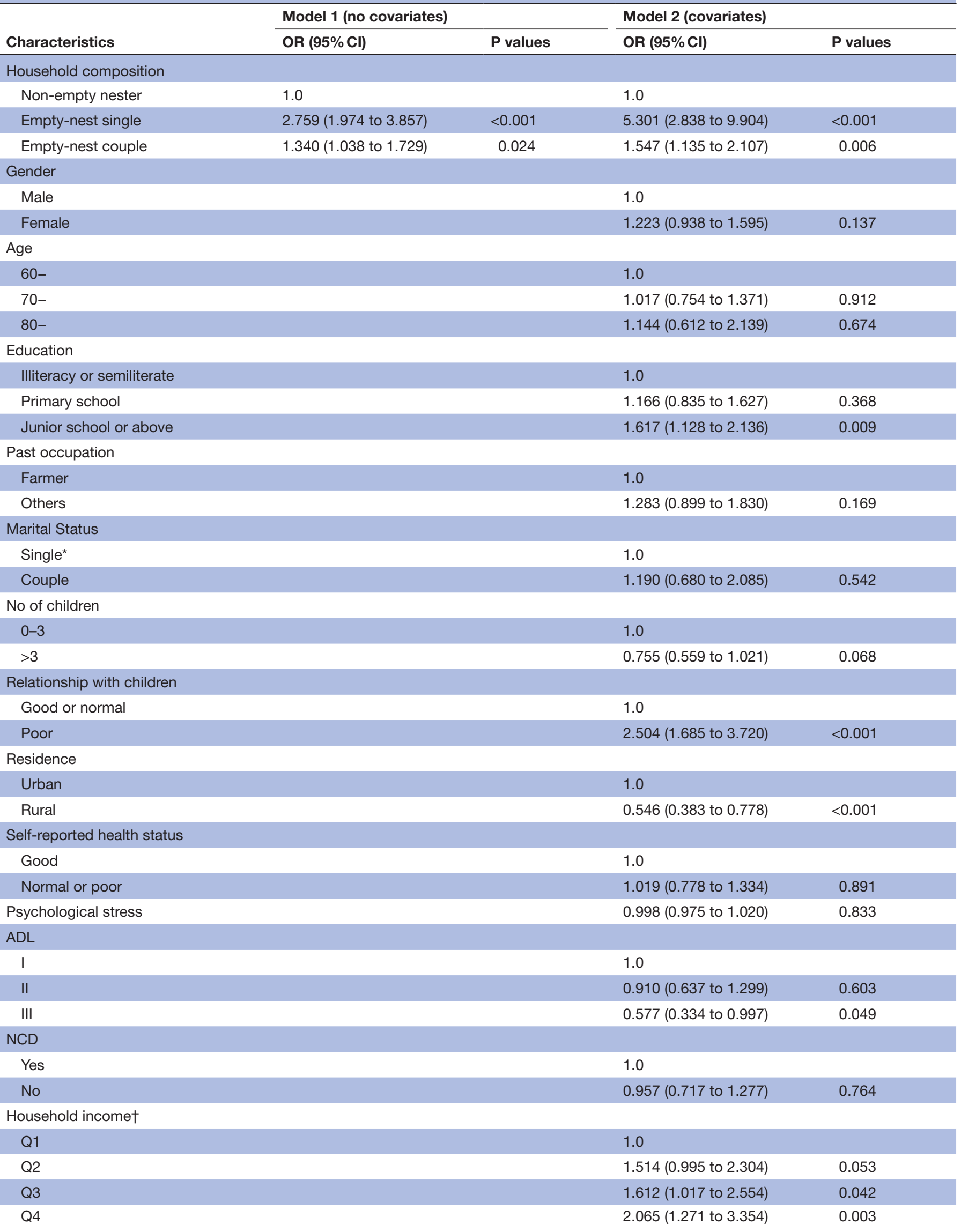


Table 2 Continued

\begin{tabular}{|c|c|c|c|c|}
\hline \multirow[b]{2}{*}{ Characteristics } & \multicolumn{2}{|c|}{ Model 1 (no covariates) } & \multicolumn{2}{|l|}{ Model 2 (covariates) } \\
\hline & OR $(95 \% \mathrm{Cl})$ & $P$ values & OR $(95 \% \mathrm{Cl})$ & $P$ values \\
\hline Per capita living space & & & 0.989 (0.983 to 0.996$)$ & 0.003 \\
\hline R squared & & 0.019 & & 0.112 \\
\hline Observations & 3923 & & & \\
\hline
\end{tabular}

*Single includes those who were unmarried (1.7\%), divorced $(0.3 \%)$, widowed $(18.6 \%)$ or separated $(0.3 \%)$.

†Quartile 1 (Q1) is the poorest and Quartile 4 (Q4) is the richest.

$\mathrm{ADL}$, activities of daily living; NCD, non-communicable disease.

illness and NCDs, which indicated that they had poorer health status than non-empty-nest elderly. ${ }^{5}$ In addition, empty-nest seniors, in comparison with non-empty-nest seniors, had higher levels of loneliness. ${ }^{33}$ The high physical and mental health service needs might be the reason why empty-nest seniors are more willing for institutional care, which can provide professional healthcare.

Consistent with previous studies, our results also showed that residence was a key predictor of willingness for institutional care in all three types of elderly households. ${ }^{34}$ Urban seniors had statistically higher willingness for institutional care than rural seniors across all three types of elderly households. Compared with rural seniors, urban seniors were less conservative. Rural seniors had lower incomes and poorer social welfare conditions than urban seniors. Further, the supply of institutional care was relatively deficient in rural areas. These differences between rural and urban areas might explain why rural seniors were less willing for institutional care. This

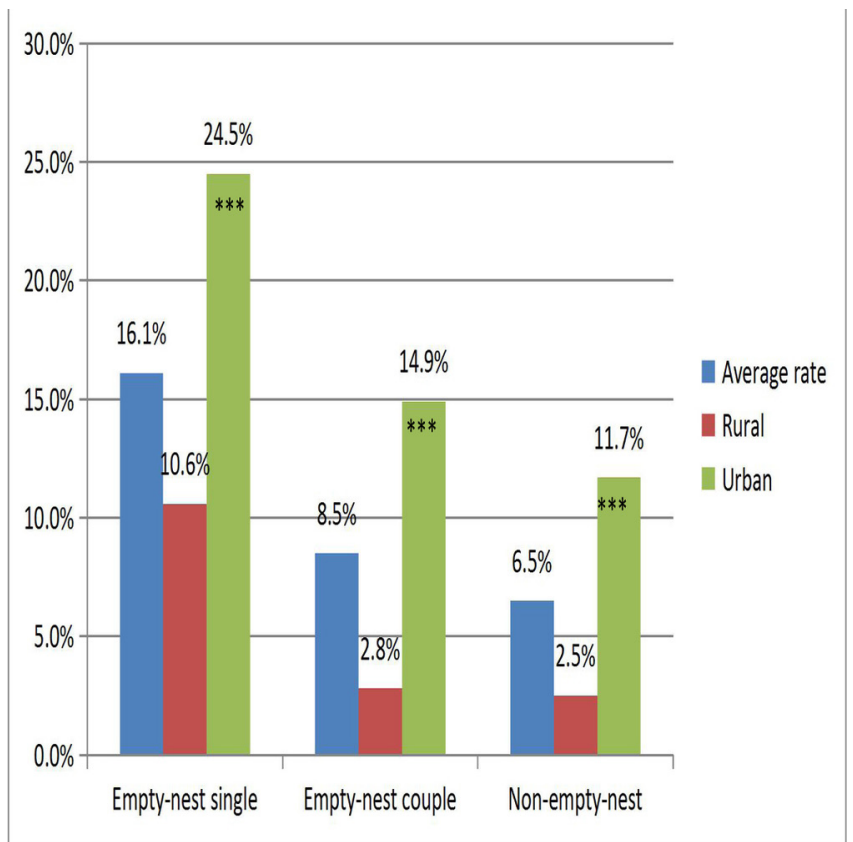

Figure 1 Prevalence of seniors' willingness for institutionalisation among empty-nest singles, emptynest couples and non-empty nesters in Shandong, China $(n=3923) .{ }^{* *} \mathrm{P}<0.001$. finding was helpful for policy-makers to differentially allocate the institutional care resources in urban and rural China.

Among empty-nest singles, psychological stress was a positive determinant for institutional care, which was in accordance with previous studies. ${ }^{35}$ To avoid excessive reliance on family members, which may result in tensions in the family, when seniors had psychological stress, they would rather choose institutional care. ${ }^{36}$ This might be associated with empty-nest singles' attitudes of self-reliance.

Similar to previous studies, empty-nest seniors who had a normal relationship with children were more willing for institutional care. ${ }^{13}$ Having a good relationship with children represents more financial assistance and spiritual comfort from children. When seniors were in a poor relationship with children, they usually relied less on their adult children, which may lead to more willingness for institutional care. Empty-nest couples with higher household income were more likely to prefer institutional care which is inconsistent with previous studies in Finland. ${ }^{37}$ Finland health system partially funds most long-term care provided at institutional facilities including health centres and nursing homes, with the maximum user fees not exceeding $80 \%$ of patients' disposable income. ${ }^{38}$ Given this, extremely high expenditures in absolute value that would be imposed on affluent patients could economically discourage them from seeking long-term institutional care. In China, most institutional care was provided by private institutions, and the charges for different services were fixed so that, compared with Finland seniors, higher-income seniors in China will not have financial concerns. It was vital to develop pro-poor institutional care policies for those lower-income emptynest seniors with high willingness for institutional care. We also found that empty-nest couples with more per capita living space were less willing for institutional care. Per capita living space actually could be a representative of wealth. Seniors with higher per capita living space might be richer, given the circumstance of China's rapidly growing housing prices. This might explain why emptynest couples with more per capita living space were more willing for institutional care. Further, empty-nest couples with an education level of junior school or above were 
Table 3 Factors associated with willingness for institutional care among older empty-nest singles in Shandong, China ( $n=391)$

Willingness for

institutionalisation

\begin{tabular}{|c|c|c|c|c|c|c|}
\hline Characteristics & Yes (\%) & No (\%) & COR $(95 \% \mathrm{Cl})$ & P values & AOR $(95 \% \mathrm{Cl})$ & $P$ values \\
\hline$n=391$ & $63(16.1)$ & $328(83.9)$ & & & & \\
\hline Gender & & & & & & NA \\
\hline Male & $21(15.9)$ & $111(84.1)$ & 1.0 & & & \\
\hline Female & $42(16.2)$ & $217(83.8)$ & 1.023 (0.578 to 1.812$)$ & 0.938 & & \\
\hline Age & & & & & & NA \\
\hline $60-$ & $27(16.7)$ & $135(83.3)$ & 1.0 & 0.708 & & \\
\hline $70-$ & $27(14.8)$ & $156(85.2)$ & 0.865 (0.484 to 1.547$)$ & 0.626 & & \\
\hline $80-$ & $9(19.6)$ & $37(80.4)$ & 1.216 (0.526 to 2.810$)$ & 0.647 & & \\
\hline Education & & & & & & NA \\
\hline Illiteracy or semiliterate & $38(15.8)$ & $202(84.2)$ & 1.0 & & & \\
\hline Primary school & $17(17.7)$ & 79 (82.3) & 1.144 (0.610 to 2.144$)$ & 0.675 & & \\
\hline Junior school or above & $8(14.5)$ & $47(85.5)$ & 0.905 (0.396 to 2.066$)$ & 0.812 & & \\
\hline Past occupation & & & & & & NA \\
\hline Farmer & $40(14.4)$ & $238(85.6)$ & 1.0 & & & \\
\hline Others & $23(20.4)$ & $90(79.6)$ & 1.521 (0.862 to 2.682) & 0.148 & & \\
\hline No of children & & & & & & NA \\
\hline $0-3$ & $38(17.9)$ & $174(82.1)$ & 1.0 & & & \\
\hline$>3$ & $25(14.0)$ & $154(86.0)$ & 0.743 (0.429 to 1.288$)$ & 0.290 & & \\
\hline Relationship with children* & & & & & & NA \\
\hline Good or normal & $39(13.1)$ & $259(86.9)$ & 1.0 & & & \\
\hline Poor & $11(22.0)$ & $39(78.0)$ & 1.873 (0.886 to 3.962$)$ & 0.101 & & \\
\hline \multicolumn{7}{|l|}{ Residence } \\
\hline Urban & $38(24.5)$ & $117(75.5)$ & 1.0 & & 1.0 & \\
\hline Rural & $25(10.6)$ & $211(89.4)$ & 0.365 (0.210 to 0.634$)$ & $<0.001$ & 0.304 (0.161 to 0.572$)$ & $<0.001$ \\
\hline Self-reported health status & & & & & & NA \\
\hline Good & $24(13.9)$ & $149(86.1)$ & 1.0 & & & \\
\hline Normal or poor & $39(17.9)$ & $179(82.1)$ & 1.353 (0.778 to 2.352$)$ & 0.284 & & \\
\hline Psychological stress $†$ & $63(16.1)$ & $328(83.9)$ & 1.036 (1.000 to 1.073$)$ & 0.050 & 1.045 (1.007 to 1.085$)$ & 0.019 \\
\hline$A D L$ & & & & & & NA \\
\hline I & $32(14.7)$ & $185(85.3)$ & 1.0 & & & \\
\hline II & $18(18.4)$ & 80 (81.6) & 1.301 (0.690 to 2.453$)$ & 0.416 & & \\
\hline III & $13(17.1)$ & $63(82.9)$ & 1.193 (0.589 to 2.415 ) & 0.624 & & \\
\hline NCD & & & & & & NA \\
\hline Yes & $50(16.9)$ & $246(83.1)$ & 1.0 & & & \\
\hline No & $13(13.7)$ & $82(86.3)$ & 0.780 (0.403 to 1.508$)$ & 0.460 & & \\
\hline \multicolumn{7}{|l|}{ Household incomeł } \\
\hline Q1 & $29(13.1)$ & $192(86.9)$ & 1.0 & & 1.0 & \\
\hline Q2 & $19(23.5)$ & $62(76.5)$ & 2.209 (1.064 to 3.869$)$ & 0.032 & 1.434 (0.721 to 2.851$)$ & 0.304 \\
\hline Q3 & $13(18.8)$ & $56(81.2)$ & 1.537 (0.749 to 3.154$)$ & 0.241 & $0.832(0.373$ to 1.858$)$ & 0.654 \\
\hline Q4 & $2(10.0)$ & $18(90.0)$ & $0.736(0.162$ to 3.337$)$ & 0.691 & 0.401 (0.084 to 1.917$)$ & 0.252 \\
\hline Per capita living space & $63(16.1)$ & 328 (83.9) & 0.997 (0.990 to 1.005$)$ & 0.504 & & NA \\
\hline
\end{tabular}

The bold values mean statistical significance.

*Forty-three of the participants are childless elders and were regarded as missing data here.

†We also included 'psychological stress' in a multivariate logistic regression model.

$\mp$ Quartile 1 (Q1) is the poorest and Quartile 4 (Q4) is the richest.

ADL, activities of daily living; AOR, adjusted OR; COR, crude OR; NA, not applicable; NCD, non-communicable disease. 
Table 4 Factors associated with willingness for institutional care among old empty-nest couples in Shandong, China ( $(n=1934)$

\begin{tabular}{|c|c|c|c|c|c|c|}
\hline \multirow[b]{2}{*}{ Characteristics } & \multicolumn{2}{|c|}{$\begin{array}{l}\text { Willingness for } \\
\text { institutionalisation }\end{array}$} & \multirow[b]{2}{*}{ COR $(95 \% \mathrm{Cl})$} & \multirow[b]{2}{*}{$P$ values } & \multirow[b]{2}{*}{ AOR $(95 \% \mathrm{Cl})$} & \multirow[b]{2}{*}{$P$ values } \\
\hline & Yes (\%) & No (\%) & & & & \\
\hline$n=1934$ & $165(8.5)$ & $1769(91.5)$ & & & & \\
\hline Gender & & & & & & NA \\
\hline Male & $83(8.4)$ & $900(91.6)$ & 1.0 & & & \\
\hline Female & $82(8.6)$ & 869 (91.4) & 1.023 (0.744 to 1.408$)$ & 0.888 & & \\
\hline Age & & & & & & NA \\
\hline $60-$ & $100(8.0)$ & $1157(92.0)$ & 1.0 & 0.384 & & \\
\hline $70-$ & $58(9.9)$ & $530(90.1)$ & $1.266(0.902$ to 1.778$)$ & 0.173 & & \\
\hline $80-$ & $7(7.9)$ & $82(92.1)$ & 0.988 (0.445 to 2.195$)$ & 0.976 & & \\
\hline \multicolumn{7}{|l|}{ Education } \\
\hline Illiteracy or semiliterate & $34(4.6)$ & $710(95.4)$ & 1.0 & & 1.0 & \\
\hline Primary school & $45(7.1)$ & $588(92.9)$ & 1.598 (1.010 to 2.528$)$ & 0.045 & $1.139(0.703$ to 1.845$)$ & 0.660 \\
\hline Junior school or above & $86(15.4)$ & $471(84.6)$ & 3.813 (2.521 to 5.767$)$ & $<0.001$ & 1.918 (1.173 to 3.135$)$ & 0.009 \\
\hline \multicolumn{7}{|l|}{ Past occupation } \\
\hline Farmer & $54(4.7)$ & $1102(95.3)$ & 1.0 & & 1.0 & \\
\hline Others & $111(14.3)$ & $667(85.7)$ & 3.396 (2.419 to 4.767$)$ & $<0.001$ & 0.909 (0.535 to 1.544$)$ & 0.724 \\
\hline \multicolumn{7}{|l|}{ No of children } \\
\hline $0-3$ & $122(9.5)$ & $1168(90.5)$ & 1.0 & & 1.0 & \\
\hline$>3$ & $43(6.7)$ & $601(93.3)$ & 0.685 (0.477 to 0.983$)$ & 0.040 & 0.878 (0.598 to 1.288$)$ & 0.506 \\
\hline \multicolumn{7}{|l|}{ Relationship with children* } \\
\hline Good or normal & $145(8.1)$ & $1637(91.9)$ & 1.0 & & 1.0 & \\
\hline Poor & $20(14.3)$ & $120(85.7)$ & $1.882(1.138$ to 3.111$)$ & 0.014 & 2.677 (1.553 to 4.615$)$ & $<0.001$ \\
\hline \multicolumn{7}{|l|}{ Residence } \\
\hline Urban & $136(14.9)$ & $776(85.1)$ & 1.0 & & 1.0 & \\
\hline Rural & $29(2.8)$ & $993(97.2)$ & 0.167 (0.110 to 0.252$)$ & $<0.001$ & $0.167(0.110$ to 0.252$)$ & $<0.001$ \\
\hline Self-reported health status & & & & & & NA \\
\hline Good & $85(8.8)$ & 877 (91.2) & 1.0 & & & \\
\hline Normal or poor & $80(8.2)$ & $892(91.8)$ & 0.925 (0.672 to 1.273$)$ & 0.634 & & \\
\hline Psychological stress & $165(8.5)$ & $1769(91.5)$ & 0.984 (0.955 to 1.014$)$ & 0.289 & & \\
\hline \multicolumn{7}{|l|}{$A D L$} \\
\hline 1 & $134(9.6)$ & $1269(90.4)$ & 1.0 & & 1.0 & \\
\hline II & $24(7.7)$ & 289 (92.3) & 0.786 (0.500 to 1.237$)$ & 0.298 & 0.905 (0.563 to 1.453$)$ & 0.678 \\
\hline III & 7 (3.2) & $211(96.8)$ & $0.314(0.145$ to 0.681$)$ & 0.003 & 0.436 (0.196 to 1.018$)$ & 0.052 \\
\hline NCD & & & & & & NA \\
\hline Yes & $118(9.1)$ & $1175(90.9)$ & 1.0 & & & \\
\hline No & $47(7.3)$ & $594(92.7)$ & 0.788 (0.554 to 1.121$)$ & 0.185 & & \\
\hline \multicolumn{7}{|l|}{ Household income $†$} \\
\hline Q1 & $11(2.0)$ & $526(98.0)$ & 1.0 & & 1.0 & \\
\hline Q2 & $34(6.2)$ & $517(93.8)$ & 3.145 (1.576 to 6.273 ) & 0.001 & 2.676 (1.326 to 5.400$)$ & 0.006 \\
\hline Q3 & $44(10.6)$ & $370(89.4)$ & 5.686 (2.898 to 11.157$)$ & $<0.001$ & 3.117 (1.430 to 6.798$)$ & 0.004 \\
\hline Q4 & $76(17.6)$ & $356(82.4)$ & 10.208 (5.348 to 19.485$)$ & $<0.001$ & 4.674 (2.057 to 10.621$)$ & $<0.001$ \\
\hline Per capita living space & $165(8.5)$ & 1769 (91.5) & 0.989 (0.980 to 0.998$)$ & 0.019 & 0.984 (0.974 to 0.995$)$ & 0.003 \\
\hline
\end{tabular}


Table 5 Factors associated with willingness for institutional care among older non-empty nesters in Shandong, China $(n=1598)$

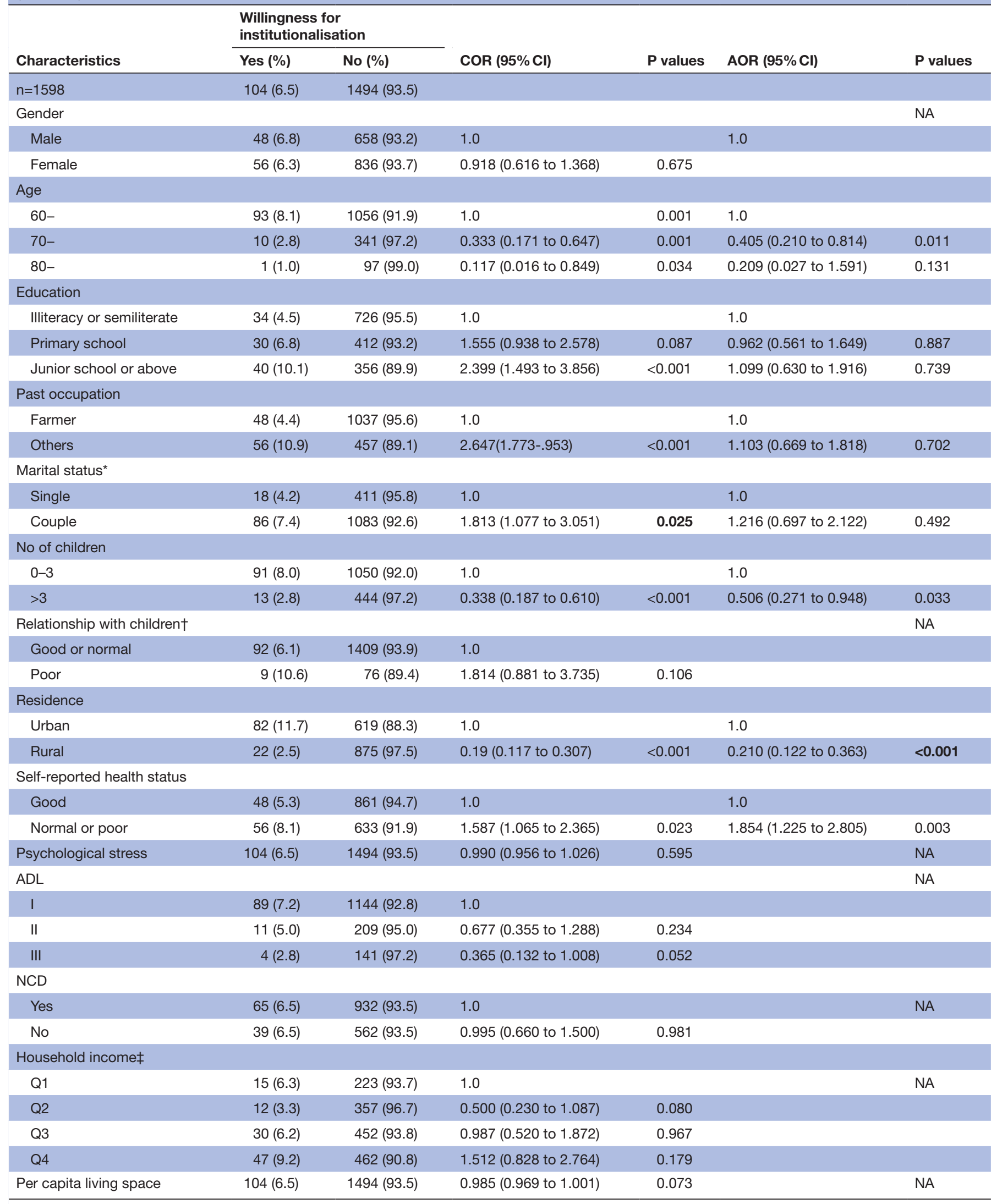

The bold values mean statistical significance.

${ }^{*}$ Single includes those who are unmarried $(0.9 \%)$, divorced $(0.3 \%)$, widowed $(25.3 \%)$ or separated $(0.3 \%)$.

$\dagger$ Twelve of the participants are childless elders and were regarded as missing data here.

$\ddagger$ Quartile 1 (Q1) is the poorest and Quartile 4 (Q4) is the richest.

ADL, activities of daily living; AOR, adjusted OR; COR, crude OR; NA, not applicable; NCD, non-communicable disease. 
more willing for institutional care, which was consistent with previous studies. ${ }^{34}$

It was found that age 70 and 79 years, having more than three children and normal self-reported health status were risk factors for non-empty nesters. Those who were age 70 and 79 had less preference for institutional care, which was inconsistent with one study in Hong Kong and other developed countries where the likelihood of elderly living in institutional care increased with age ${ }^{39}{ }^{40}$ Hong Kong and other developed countries are more developed and open than Shandong, which makes those seniors more open minded about institutional care. Different value concepts about institutional care might explain why those seniors were more willing for institutional care when compared with Shandong seniors. Non-empty-nest seniors who had more than three children were less willing for institutional care. More children usually mean more financial and physical assistance, so it might reduce elderly needs for institutional care. ${ }^{10}$

This study had a large size sample (nearly 4000), which is much larger than that used in most of the similar studies. This gave the study a high degree of statistical power. This study had some limitations. First, our study had a cross-sectional design, and the results could not be interpreted as cause and effect. Second, all data were based on self-reported measures, which could lead to recall biases. Third, even though we have included some variables of social support in this study (eg, living arrangements of the elderly households, number of the children and relationship with children), we did not use a scale to measure social support of the seniors, which will be remedied in a future study. Finally, our investigation was conducted in Shandong province, which is rather a conservative region, thus, the results of our study may not be generalised to other parts of China.

\section{CONCLUSION}

Our study suggested that the living arrangements of households with seniors were associated with the willingness for institutional care of the elderly in China, and empty nesters were more willing for institutional care than their counterparts. Our results also showed that residence was a key associated factor for willingness for institutional care in all three types of elderly households. The government should pay more attention to institutional care in rural areas where there is still a gap in elder care when compared with that in urban areas. Furthermore, we also identified some other associated factors for institutional care willingness among each type of elderly household. Targeting policies should be developed to offer appropriate institutional care for different types of seniors.

Acknowledgements We thank the officials of local health agencies and all participants and staff at the study sites for their cooperation.

Contributors $\mathrm{CZ}, \mathrm{YQ}$ and $\mathrm{WQ}$ conceived the idea, $\mathrm{CZ}$ implemented the field study. $C Z, Y Q, D G$ and $L Z$ participated in the statistical analysis and interpretation of the results. YQ drafted the manuscript. CZ, WQ and LS gave many valuable comments on the draft and polished it. All authors read and approved the final manuscript.

Funding This study was funded by the National Natural Science Foundation of China (7100306,71473152 and 71774104), Cheeloo Young Scholar Grant and Shandong University (IFYT1810, 2012DX006).

Competing interests None declared.

Patient consent Obtained.

Ethics approval Ethical approval was obtained from The Ethical Committee of Shandong University School of Public Health.

Provenance and peer review Not commissioned; externally peer reviewed.

Data sharing statement No additional data are available.

Open access This is an open access article distributed in accordance with the Creative Commons Attribution Non Commercial (CC BY-NC 4.0) license, which permits others to distribute, remix, adapt, build upon this work non-commercially, and license their derivative works on different terms, provided the original work is properly cited, appropriate credit is given, any changes made indicated, and the use is non-commercial. See: http://creativecommons.org/licenses/by-nc/4.0/.

\section{REFERENCES}

1. Chinese National Commission of Aging. China stepped into aging society in 1999, and the number of the elderly ranks in the first in the world, 2006.

2. National Bureau of Statistics of the People's Republic of China. Population map of China's economy, and a rapidly aging population in society, 2015.

3. United Nations. World population prospects the 2010 revision, 2011:9.

4. Liu LJ, Guo Q. Life satisfaction in a sample of empty-nest elderly: a survey in the rural area of a mountainous county in China. Qual Life Res 2008;17:823-30.

5. Zhou C, Ji C, Chu J, et al. Non-use of health care service among empty-nest elderly in Shandong, China: a cross-sectional study. BMC Health Serv Res 2015;15:1-10.

6. Liu T, Sun L. An apocalyptic vision of ageing in China: Old age care for the largest elderly population in the world. Zeitschrift für Gerontologie und Geriatrie 2015;48:354-64.

7. Zhan HJ, Liu G, Guan X, et al. Recent developments in institutional elder care in China: changing concepts and attitudes. J Aging Soc Policy 2006;18:85-108.

8. CROLL EJ. The intergenerational contract in the changing Asian Family. Oxford Development Studies 2006;34:473-91.

9. Lin Z, Pei X. Intergenerational exchange of resources and elderly support in rural China. Int J Aging Hum Dev 2016;83:108-27.

10. Zhan HJ, Montgomery RJV. Gender and elder care In China: the influence of filial piety and structural constraints. Gender \& Society 2003;17:209-29.

11. Zhan HJ, Liu G, Guan X. Willingness and availability: Explaining new attitudes toward institutional elder care among Chinese elderly parents and their adult children. J Aging Stud 2006;20:279-90.

12. Xu Q. Status quo and problems of old age support by youth and adult within the family (in Chinese). Sociological Research 1994:80-4.

13. Chou RJ-ANN. Willingness to live in eldercare institutions among older adults in urban and rural China: a nationwide study. Ageing Soc 2010;30:583-608.

14. Cheng Y, Rosenberg MW, Wang W, et al. Access to residential care in Beijing, China: making the decision to relocate to a residential care facility. Ageing Soc 2012;32:1277-99.

15. Peng R, Wu B. Changes of health status and institutionalization among older adults in China. J Aging Health 2015;27:1223-46.

16. Guan X, Zhan HJ, Liu G. Institutional and individual autonomy: investigating predictors of attitudes toward institutional care in China. Int J Aging Hum Dev 2007;64:83-107.

17. Chen J. Willingness for institutional care and its influencing factors in the empty-nest seniors: An empirical study in Suzhou city, China. Modern Preventive Medicine 2015;142:1660-2. (in Chinese).

18. Xie X, Chen L, Peng Y, et al. Population and development. 2010;16:67-75. (in Chinese).

19. Zhu A, Liu $Q$, Cao $C$, et al. Willingness for institutional care and its influencing factors among the empty-nest seniors in Hangzhou, China. Preventive Medicine 2017;29.

20. Shandong Provincial Statistics Bureau. Shandong statistic year book, 2015. 
21. Qian Y, Chu J, Ge D, et al. Gender difference in utilization willingness of institutional care among the single seniors: evidence from rural Shandong, China. Int J Equity Health 2017;16:77.

22. Zhou C, Chu J, Liu D, et al. Comparison of health need and utilization between empty-nest and non-empty-nest aging population in urban communities: a sample survey based on Jinan city. Chinese Journal of Health Policy 2012;05:24-9. (in Chinese).

23. Kessler RC, Andrews G, Colpe LJ, et al. Short screening scales to monitor population prevalences and trends in non-specific psychological distress. Psychol Med 2002;32:959-76.

24. Zhou C, Chu J, Wang T, et al. Reliability and validity of 10 -item kessler scale $(\mathrm{k} 10)$ chinese version in evaluation of mental health status of chinese population (in Chinese). Chinese Journal of Clinical Psychology 2008;16:627-9.

25. Lawton MP, Brody EM. Assessment of older people: selfmaintaining and instrumental activities of daily living. Gerontologist 1969;9:179-86.

26. Feng J. Daily activities of living scale's application value in patients in respiratory medicine (in Chinese). Hebei Medical Journal 2013;35:3346-8.

27. Mahoney FI, Barthel DW. Functional evaluation: the barthel index. Md State Med J 1965;14:61-5.

28. Jang $Y, \operatorname{Kim} \mathrm{G}$, Chiriboga DA, et al. Willingness to use a nursing home: a study of korean american elders. J Appl Gerontol 2008;27:110-7.

29. Chung $\mathrm{MH}, \mathrm{Hsu} \mathrm{N}$, Wang $\mathrm{YC}$, et al. Factors affecting the longterm care preferences of the elderly in Taiwan. Geriatr Nurs 2008;29:293-301.

30. Jiang $Y-x$, Si W. Analysis of the factors influencing on elders' preferences for social care: empirical evidence from Zhejiang Province (in Chinese). Population \& Economics 2006:8-12.
31. Deng Y, Li N, Liu C, et al. Laonianren yanglao moushi xienzhe de yinxiang yinshu yianjiu [Factors affecting older adults' choices in types of eldercare] (in Chinese). China Journal of Public Health 2008;19:731-2.

32. Grundy E, Jitlal M. Socio-demographic variations in moves to institutional care 1991-2001: a record linkage study from England and Wales. Age Ageing 2007;36:424-30.

33. Liu LJ, Guo Q. Loneliness and health-related quality of life for the empty nest elderly in the rural area of a mountainous county in China. Qual Life Res 2007;16:1275-80.

34. Nie A, Cao F, Shao D. Endowment and living willingness and its influence factors of the elderly: based on CSS 2011: Chinese Public Administration, 2015.

35. Branch LG, Jette AM. A prospective study of long-term care institutionalization among the aged. Am J Public Health 1982;72:1373-9.

36. Tao T, Cong C. An analysis of influencing factors on elder's preference for patterns of old-age support: some empirical evidence from beijing xicheng district (in Chinese). Population \& Economics 2014:15-22.

37. Einiö EK. Determinants of instituional care at older ages in Finland: The Population Reseach Institute, 2010.

38. Nihtilä E, Martikainen P. Household income and other socioeconomic determinants of long-term institutional care among older adults in Finland. Popul Stud 2007;61:299-314.

39. Woo J, Ho SC, Lau J, et al. Age and marital status are major factors associated with institutionalisation in elderly Hong Kong Chinese. $J$ Epidemiol Community Health 1994;48:306-9.

40. Wingard DL, Jones DW, Kaplan RM. Instituional care utilization by the elderly: a critical review. The Geontologicla Society of American 1987;27:156-63. 